\title{
Magnetoresistance and phase composition of La-Sn-Mn-O systems
}

\author{
Li, Z.W.; Morrish, A.H.; Jiang, Jianzhong
}

Published in:

Physical Review B

Link to article, DOI:

10.1103/PhysRevB.60.10284

Publication date:

1999

Document Version

Publisher's PDF, also known as Version of record

Link back to DTU Orbit

Citation (APA):

Li, Z. W., Morrish, A. H., \& Jiang, J. (1999). Magnetoresistance and phase composition of La-Sn-Mn-O systems. Physical Review B, 60(14), 10284. https://doi.org/10.1103/PhysRevB.60.10284

\section{General rights}

Copyright and moral rights for the publications made accessible in the public portal are retained by the authors and/or other copyright owners and it is a condition of accessing publications that users recognise and abide by the legal requirements associated with these rights.

- Users may download and print one copy of any publication from the public portal for the purpose of private study or research.

- You may not further distribute the material or use it for any profit-making activity or commercial gain

- You may freely distribute the URL identifying the publication in the public portal

If you believe that this document breaches copyright please contact us providing details, and we will remove access to the work immediately and investigate your claim. 


\title{
Magnetoresistance and phase composition of La-Sn-Mn-O systems
}

\author{
Z. W. Li and A. H. Morrish \\ Department of Physics, University of Manitoba, Winnipeg, Canada R3T 2N2 \\ J. Z. Jiang \\ Department of Physics, Technical University of Denmark, DK3800, Lyngby, Denmark
}

(Received 22 April 1999)

\begin{abstract}
The transport properties of the manganites $\mathrm{La}_{1-x} \mathrm{Sn}_{x} \mathrm{MnO}_{3+\delta}$ with $x=0.1-0.5$ and of Fe-doped samples have been comprehensively studied using magnetoresistance measurements, ${ }^{57} \mathrm{Fe}$ and ${ }^{119} \mathrm{Sn}$ Mössbauer spectroscopy, and $\mathrm{x}$-ray diffraction. At the $\mathrm{Sn}$ concentration $x=0.5, \mathrm{La}_{0.5} \mathrm{Sn}_{0.5} \mathrm{MnO}_{3+\delta}$, is a single phase. The manganites $\mathrm{La}_{1-x} \mathrm{Sn}_{x} \mathrm{MnO}_{3+\delta}$ with $x<0.5$ consist of two phases, $A B \mathrm{O}_{3}$ and $A_{2} B_{2} \mathrm{O}_{7}$; the chemical formulas are $\mathrm{LaMnO}_{3+\delta}$ and $\left(\mathrm{La}_{0.5} \mathrm{Sn}_{0.5}\right)_{2} \mathrm{Mn}_{2} \mathrm{O}_{7}$, respectively. The colossal magnetoresistance (CMR) in $\mathrm{La}_{1-x} \mathrm{Sn}_{x} \mathrm{MnO}_{3+\delta}$ appears to have its origin in deficient $\mathrm{La}$ and/or $\mathrm{Mn}$ ions in the $A B \mathrm{O}_{3}$ phase. Mössbauer spectra show that a superparamagnetic doublet exists from $T=250-77 \mathrm{~K}$ for the $A B \mathrm{O}_{3}$ phase in the Fe-doped sample and may have superparamagneticlike spin clusters that lead to a low saturation field. Consequently, the CMR reaches $75 \%$ at an applied field of only $20 \mathrm{kOe}$ for the Fe-doped sample; however, the same CMR requires fields as high as $70 \mathrm{kOe}$ in the undoped $\mathrm{La}_{0.7} \mathrm{Sn}_{0.3} \mathrm{MnO}_{3+\delta}$ sample. [S0163-1829(99)02437-6]
\end{abstract}

\section{INTRODUCTION}

Generally, manganites with colossal magnetoresistance (CMR) can be classified into two categories. One is the perovskite-type compound $\left(\mathrm{ABO}_{3}\right)$ with a chemical formula $\left(R_{1-x}^{3+} D_{x}^{2+}\right)\left(\mathrm{Mn}_{1-x}^{3+} \mathrm{Mn}_{x}^{4+}\right) \mathrm{O}_{3} \quad(R=$ rare-earth and $D=\mathrm{Ca}$, $\mathrm{Sr}, \mathrm{Ba}, \mathrm{Pb}$, and $\mathrm{Cd}$, all divalent). ${ }^{1}$ The other is the pyrochlore-type compound $\left(A_{2} B_{2} \mathrm{O}_{7}\right)$ with the formula $\mathrm{Tl}_{2}^{3+} \mathrm{Mn}_{2}^{4+} \mathrm{O}_{7} \cdot{ }^{2,3}$

Recently, it has been discovered that $\mathrm{La}_{0.7} \mathrm{Sn}_{0.3} \mathrm{MnO}_{3+\delta}$ exhibits CMR near room temperature. Its magnetoresistivity coefficient (classical) is as high as $74 \%$ for $H=70 \mathrm{kOe}^{4}$ Further investigation showed that this manganite consists of two phases; one is the perovskite-type $\mathrm{ABO}_{3}$ and the other is the pyrochlore-type $A_{2} B_{2} \mathrm{O}_{7} .{ }^{5}$ Krivoruchko et al. ${ }^{6}$ reported compositions of the two phases, $\mathrm{La}_{0.4} \square_{0.6} \mathrm{MnO}_{3-\delta}$ for the $A B \mathrm{O}_{3}$ phase and $\mathrm{La}_{2} \mathrm{Sn}_{2} \mathrm{O}_{7}$ for the $A_{2} B_{2} \mathrm{O}_{7}$ phase. However, it is hard to believe that the perovskite structure can be maintained for so large a deficiency of La ions.

Fe doping can significantly modify the magnetic and transport properties of manganites. ${ }^{7-9}$ An increase in CMR for Fe-doped samples has been reported in La-Ca-Mn-O systems ${ }^{8}$ and La-Sn-Mn-O systems. ${ }^{7}$ A metalliclike conductivity and ferromagnetic ground state for the perovskite compound $\mathrm{La}_{1-x} \mathrm{M}_{x}^{2+} \mathrm{MnO}_{3}$ are attributed to the doubleexchange model which involves electron exchange between neighboring $\mathrm{Mn}^{3+}$ and $\mathrm{Mn}^{4+}$ sites. The correlations between transport behavior and magnetic properties have been studied. ${ }^{10-12}$ Some models, such as the Kondo model and the polaron model have been proposed to describe the correlations for the La-Sr-Mn-O and La-Ca-Mn-O systems. However, the origin of the increase in CMR for Fe-doped samples, as far as we know, has not been proposed up to now. In this work, based on our Mössbauer spectra, a superparamagneticlike model is proposed to describe the properties for Fe-doped La-Sn-Mn-O systems. In addition, the compositions of the two phases in La-Sn-Mn-O were determined by $\mathrm{x}$ ray as well as ${ }^{57} \mathrm{Fe}$ and ${ }^{119} \mathrm{Sn}$ Mössbauer spectra.

\section{EXPERIMENTAL}

Samples of $\mathrm{La}_{1-x} \mathrm{Sn}_{x} \mathrm{MnO}_{3+\delta}$ with $x=0.1,0.2,0.3$, and 0.5 as well as Fe-doped $\mathrm{La}_{1-x} \mathrm{Sn}_{x} \mathrm{Mn}_{0.985} \mathrm{Fe}_{0.015}^{57} \mathrm{O}_{3+\delta}$ with $x=0.3$ and 0.5 were synthesized using conventional ceramic techniques. A mixture of oxides $\mathrm{La}_{2} \mathrm{O}_{3}, \mathrm{SnO}_{2}, \mathrm{MnO}_{2}$, and ${ }^{57} \mathrm{Fe}_{2} \mathrm{O}_{3}$ of stoichometric composition was presintered at $800{ }^{\circ} \mathrm{C}$ for $10 \mathrm{~h}$ and then crushed. The samples were shaped and sintered in $\mathrm{O}_{2}$ at $1200{ }^{\circ} \mathrm{C}$ for $6 \mathrm{~h}$ and followed by annealing at $900{ }^{\circ} \mathrm{C}$ for $24 \mathrm{~h}$.

X-ray diffraction (XRD) was performed with a Philips diffractometer using $\mathrm{Cu} K \alpha$ radiation. The magnetoresistances were examined at 4.2-300 K with zero field and up to $70 \mathrm{kOe}$ applied field using the standard four-probe method. ${ }^{57} \mathrm{Fe}$ Mössbauer spectra from $4.2 \mathrm{~K}$ to room temperature and ${ }^{119} \mathrm{Sn}$ Mössbauer spectra at room temperature were taken with a conventional constant acceleration spectrometer. The $\gamma$-ray sources were ${ }^{57} \mathrm{Co}$ in a $\mathrm{Rh}$ matrix and ${ }^{119} \mathrm{Sn}$ in $\mathrm{BaSnO}_{3}$. All isomer shifts are given relative to that of $\alpha-\mathrm{Fe}$ at room temperature.

\section{RESULTS}

\section{A. Magnetoresistance \\ 1. CMR for La-Sn-Mn-O}

The transport properties of $\mathrm{La}_{1-x} \mathrm{Sn}_{x} \mathrm{MnO}_{3+\delta}(x=0.1$, $0.2,0.3$, and 0.5) are shown in Table I. $\mathrm{La}_{0.5} \mathrm{Sn}_{0.5} \mathrm{MnO}_{3+\delta}$ is an insulator; the other samples are electrical conductors. The resistivities at room temperature increase with Sn substitutions; they are $0.036,0.064$, and $0.20 \Omega \mathrm{cm}$ for the samples with $\mathrm{Sn}$ concentrations $x=0.1,0.2$, and 0.3 , respectively. The manganites $\mathrm{La}_{1-x} \mathrm{Sn}_{x} \mathrm{MnO}_{3+\delta}$ have a semiconductormetal transition (S-M transition) at $235-245 \mathrm{~K}$. The maxi- 
TABLE I. Transport properties of $\mathrm{La}_{1-x} \mathrm{Sn}_{x} \mathrm{MnO}_{3+\delta}$.

\begin{tabular}{lccccc}
\hline \hline$x$ & $\begin{array}{c}\rho(0) \\
(\Omega \mathrm{cm})\end{array}$ & $\begin{array}{c}\rho(H=0) \\
(\Omega \mathrm{cm})\end{array}$ & $\begin{array}{c}\rho(H=15 \mathrm{kOe}) \\
(\Omega \mathrm{cm})\end{array}$ & $\begin{array}{c}\mathrm{MR}(\%) \\
\%\end{array}$ & $T_{\mathrm{S}-\mathrm{M}}(\mathrm{K})$ \\
\hline 0.1 & 0.036 & 0.080 & 0.057 & -29 & 245 \\
0.2 & 0.064 & 0.150 & 0.115 & -23 & 240 \\
0.3 & 0.20 & 0.61 & 0.46 & -25 & 235 \\
$0.3^{\mathrm{a}}$ & 0.73 & 7.45 & 2.38 & -74 & 195 \\
0.5 & Insulator & & & & \\
\hline \hline
\end{tabular}

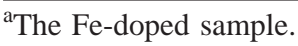

mum magnetoresistance (MR) effect occurs at the transition temperatures, as shown in Fig. 1. The magnetoresistance coefficient, defined as

$\mathrm{MR}=-\Delta \rho / \rho \times 100 \%=[\rho(\mathrm{H}, \mathrm{T})-\rho(0, T)] / \rho(0, T) \times 100 \%$

in $\mathrm{H}=15 \mathrm{kOe}$ are 29,23 , and $25 \%$ for the samples with $x$ $=0.1,0.2$, and 0.3 , respectively.

\section{The effect of Fe doping on CMR}

A small amount of Fe doping modifies the magnetoresistance of the La-Sn-Mn-O systems. First, the resistivity at room temperature is about triple and the maximum resistivity at the S-M transition temperature is over 10 times greater for the Fe-doped sample, $\mathrm{La}_{0.7} \mathrm{Sn}_{0.3} \mathrm{Mn}_{0.985} \mathrm{Fe}_{0.015}^{57} \mathrm{O}_{3+\delta}$, than its parent. Second, the $\mathrm{S}-\mathrm{M}$ transition temperature is reduced by $40 \mathrm{~K}$, viz. from $235 \mathrm{~K}$ for $\mathrm{La}_{0.7} \mathrm{Sn}_{0.3} \mathrm{MnO}_{3+\delta}$ to $195 \mathrm{~K}$ for the Fe-doped sample. Mössbauer spectra show that Fe moments are antiparallel to the Mn moments, as described in Sec. III C 2. The antiferromagnetic $\mathrm{Fe}-\mathrm{O}-\mathrm{Mn}$ superexchange interaction can weaken the double-exchange interaction between $\mathrm{Mn}^{3+}$ and $\mathrm{Mn}^{4+}$ ions, which leads to an increase in the resistivity and a decrease in the S-M transition temperature.

More importantly, Fe doping can reduce the saturation field of the magnetoresistance effect. Figure 2 shows the dependence of MR on the applied fields $H$ for

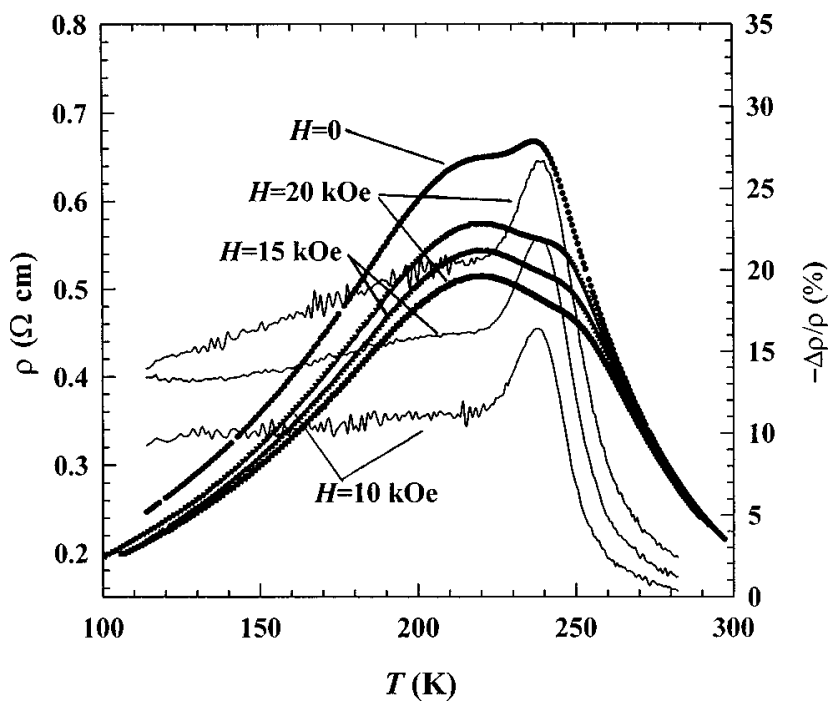

FIG. 1. Resistivity-temperature curves (solid points) in zero as well as 10, 15, and $20 \mathrm{kOe}$ applied field and the corresponding magnetoresistance coefficient-temperature curves (solid line) for $\mathrm{La}_{0.7} \mathrm{Sn}_{0.3} \mathrm{MnO}_{3+\delta}$.

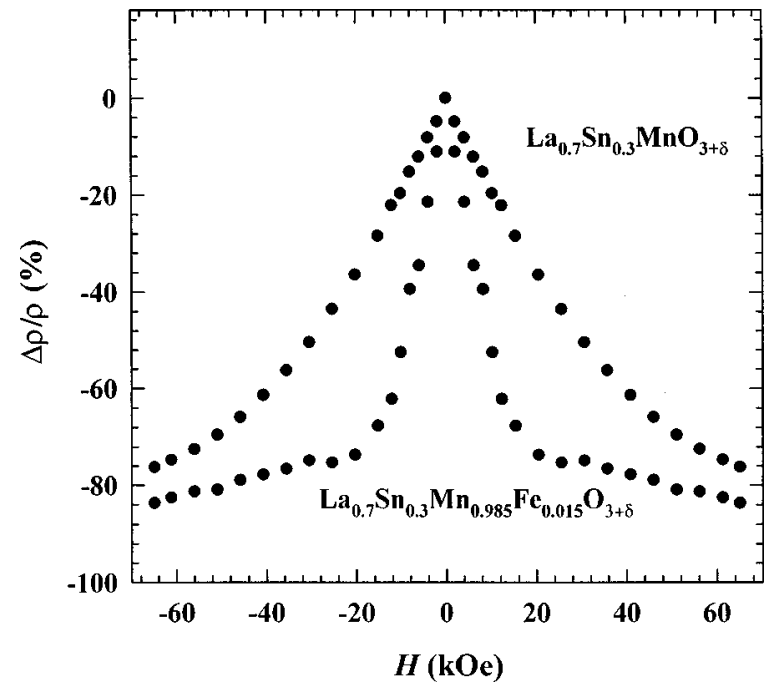

FIG. 2. The magnetoresistance coefficient-applied field curves at $\mathrm{S}-\mathrm{M}$ transition temperature, $T_{\mathrm{S}-\mathrm{M}}=235 \mathrm{~K}$ and $195 \mathrm{~K}$ for $\mathrm{La}_{0.7} \mathrm{Sn}_{0.3} \mathrm{MnO}_{3+\delta}$ and $\mathrm{La}_{0.7} \mathrm{Sn}_{0.3} \mathrm{Mn}_{0.985} \mathrm{Fe}_{0.015} \mathrm{O}_{3+\delta}$, respectively.

$\mathrm{La}_{0.7} \mathrm{Sn}_{0.3} \mathrm{MnO}_{3+\delta}$ and $\mathrm{La}_{0.7} \mathrm{Sn}_{0.3} \mathrm{Mn}_{0.985} \mathrm{Fe}_{0.015}^{57} \mathrm{O}_{3+\delta}$. For $\mathrm{La}_{0.7} \mathrm{Sn}_{0.3} \mathrm{MnO}_{3+\delta}$, the MR does not reach saturation even if the field is as high as $70 \mathrm{kOe}$. However, for the Fe-doped sample, at $H=20 \mathrm{kOe}$, the MR is close to saturation. Consequently, although in a high field the MR is almost the same for both, in a low field such as $H=20 \mathrm{kOe}$, the MR is much superior for the Fe-doped sample than for its parent $\mathrm{La}_{1-x} \mathrm{Sn}_{x} \mathrm{MnO}_{3+\delta}$. The MR is as large as $75 \%$ at the applied field of $20 \mathrm{kOe}$ for the Fe-doped sample; however, to obtain the same MR, a field at as high as $70 \mathrm{kOe}$ is required for $\mathrm{La}_{0.7} \mathrm{Sn}_{0.3} \mathrm{MnO}_{3+\delta}$.

\section{B. X-ray diffraction}

The $\mathrm{X}$-ray diffraction (XRD) patterns for $\mathrm{La}_{1-x} \mathrm{Sn}_{x} \mathrm{MnO}_{3+\delta}$ with $x=0.1,0.2,0.3$, and 0.5 are shown in Fig. 3. The lattice parameters are listed in Table II. Only the sample with $x=0.5$ is a single phase that has the cubic structure. The positions and intensities of the XRD are similar to those for $\mathrm{La}_{2} \mathrm{Sn}_{2} \mathrm{O}_{7}$ (Ref. 13) and $\mathrm{Tl}_{2} \mathrm{Mn}_{2} \mathrm{O}_{7} \cdot{ }^{3}$ The other samples $(x=0.1,0.2$, and 0.3$)$ are mixtures of the two phases. One is $A_{2} B_{2} \mathrm{O}_{7}$; the other is $A B \mathrm{O}_{3}$ with the monoclinic or rhombohedral structure, respectively, similar to $\mathrm{La}_{0.8} \mathrm{Sr}_{0.2} \mathrm{MnO}_{3}$ (Ref. 14) or $\mathrm{La}_{2 / 3} \mathrm{~Pb}_{1 / 3} \mathrm{MnO}_{3}$. However, the double rhombohedral structure ${ }^{15}$ is excluded because the (113) XRD line is not observed. In Fig. 3, the indexing is based on the monoclinic structure. With increasing $\mathrm{Sn}$ concentration, the intensities of the XRD decrease for $A B \mathrm{O}_{3}$ and increase for $A_{2} B_{2} \mathrm{O}_{7}$.

In order to obtain the volume fraction for the two phases, a series of mixtures of $\left(\mathrm{La}_{0.5} \mathrm{Sn}_{0.5}\right)_{2} \mathrm{Mn}_{2} \mathrm{O}_{7}$ and $\mathrm{LaMnO}_{3}$ with known weight fractions were made. The intensities of (440) XRD lines in $A_{2} B_{2} \mathrm{O}_{7}$ and of (220) lines in $A B \mathrm{O}_{3}$ were measured. The intensity ratios as a function of the volume fractions or weight fractions, were plotted. Based on the standard curve, the volume fractions of $A B \mathrm{O}_{3}$ and $A_{2} B_{2} \mathrm{O}_{7}$ are obtained for $\mathrm{La}_{1-x} \mathrm{Sn}_{x} \mathrm{MnO}_{3+\delta}$ and the results are also listed in Table II. 


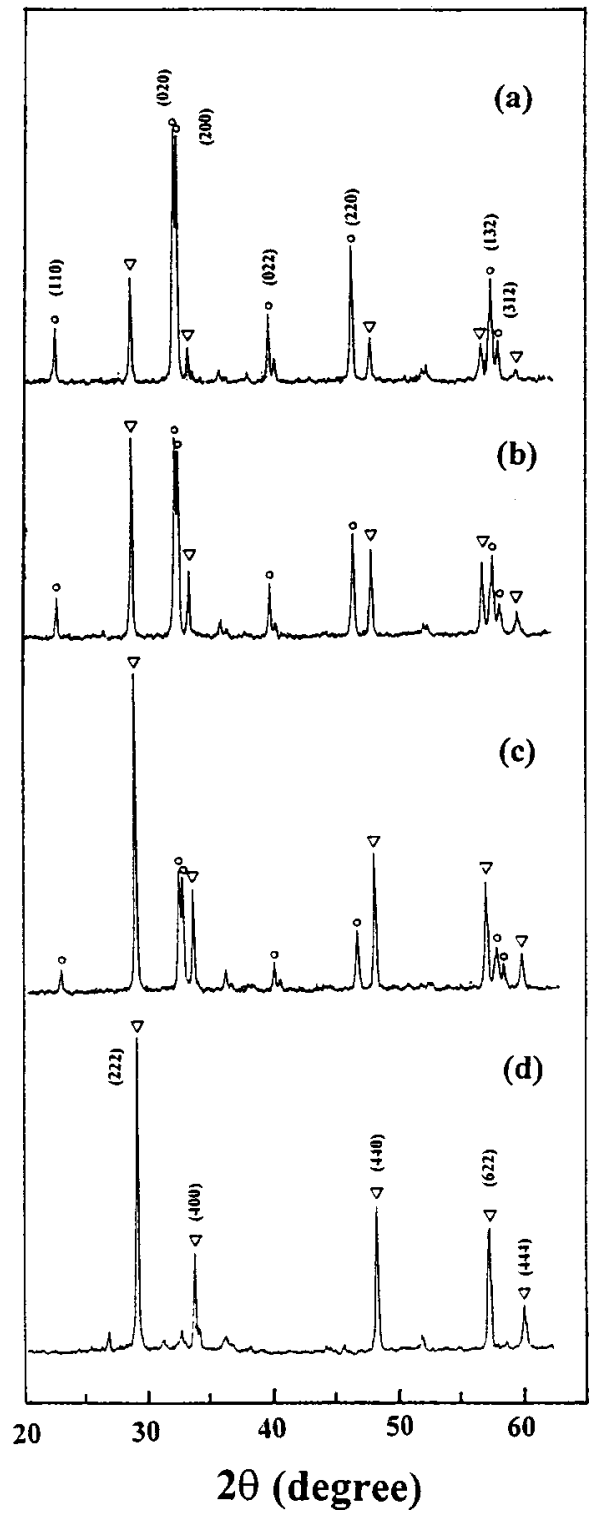

FIG. 3. X-ray-diffraction patterns for $\mathrm{La}_{1-x} \mathrm{Sn}_{x} \mathrm{MnO}_{3+\delta}$ with (a) $x=0.1$, (b) $x=0.2$, (c) $x=0.3$, and (d) $x=0.4$. The circles and triangles represent the $A B \mathrm{O}_{3}$ and $A_{2} B_{2} \mathrm{O}_{7}$ phases, respectively.

\section{Mössbauer spectra}

\section{1. ${ }^{57} \mathrm{Fe}$ and ${ }^{119} \mathrm{Sn}$ Mössbauer spectra at room temperature}

${ }^{57} \mathrm{Fe}$ Mössbauer spectra of $\mathrm{La}_{1-x} \mathrm{Sn}_{x} \mathrm{Mn}_{0.985} \mathrm{Fe}_{0.015} \mathrm{O}_{3+\delta}$ with $x=0.3$ and 0.5 at room temperature are shown in Fig. 4 . Fitted hyperfine parameters are listed in Table III. The spec-

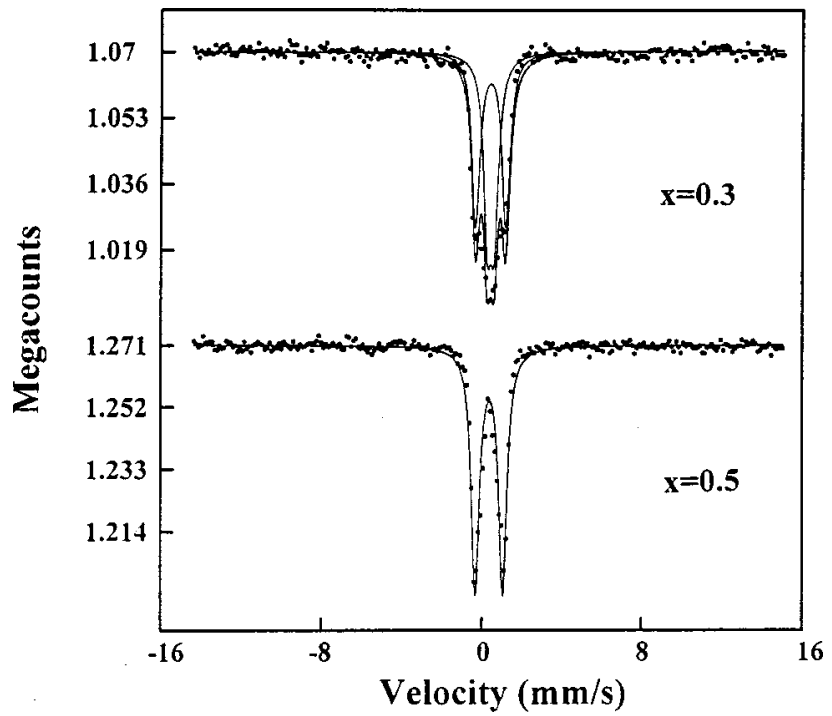

FIG. 4. ${ }^{57} \mathrm{Fe}$ Mössbauer spectra at room temperature for $\mathrm{La}_{1-x} \mathrm{Sn}_{x} \mathrm{Mn}_{0.985} \mathrm{Fe}_{0.015} \mathrm{O}_{3+\delta}$ with $x=0.3$ and 0.5 .

trum of sample with $x=0.5$ is a doublet; the isomer shift and quadrupole splitting are 0.35 and $1.47 \mathrm{~mm} / \mathrm{s}$, respectively. The spectrum of sample with $x=0.3$ consists of two doublets.

For the outer one, the isomer shift and quadrupole splitting are 0.36 and $1.51 \mathrm{~mm} / \mathrm{s}$, respectively, almost the same as the sample with $x=0.5$. This doublet is assigned to the $A_{2} B_{2} \mathrm{O}_{7}$ phase. For the inner one, the isomer shift and quadrupole splitting are 0.37 and $0.38 \mathrm{~mm} / \mathrm{s}$; this doublet is assigned to the $A B \mathrm{O}_{3}$ phase. The values of isomer shifts $(0.35-0.38 \mathrm{~mm} / \mathrm{s})$ indicate that all $\mathrm{Fe}$ ions are in the ferric $\left(\mathrm{Fe}^{3+}\right)$ state for the two phases.

${ }^{119} \mathrm{Sn}$ Mössbauer spectra of $\mathrm{La}_{1-x} \mathrm{Sn}_{x} \mathrm{MnO}_{3+\delta}$ with $x$ $=0.3$ and 0.5 at room temperature consist of one doublet, as shown in Fig. 5. Both have almost the same isomer shift and quadrupole splitting. The isomer shifts are 0.15(2) and $0.16(2) \mathrm{mm} / \mathrm{s}$ and the quadrupole splittings are $0.52(2)$ and $0.65(2) \mathrm{mm} / \mathrm{s}$, respectively, for the samples with $x=0.3$ and 0.5 . It is known that the range of isomer shifts are $0.00-1.30$ for $\mathrm{Sn}^{4+}$ and 2.30-4.44 mm/s for $\mathrm{Sn}^{2+}$. Hence, the isomer shift of $0.15 \mathrm{~mm} / \mathrm{s}$ implies that all $\mathrm{Sn}$ ions are in the $4+$ valence state for the samples with $x=0.3$ and 0.5 .

\section{2. ${ }^{57} \mathrm{Fe}$ Mössbauer spectra at $4.2 \mathrm{~K}$}

Mössbauer spectra of $\mathrm{La}_{1-x} \mathrm{Sn}_{x} \mathrm{Mn}_{0.985} \mathrm{Fe}_{0.015} \mathrm{O}_{3+\delta}(x$ $=0.3$ and 0.5 ) at $T=4.2 \mathrm{~K}$ are shown in Fig. 6 and the fitted

TABLE II. Structure parameters of $\mathrm{La}_{1-x} \mathrm{Sn}_{x} \mathrm{MnO}_{3+\delta}$.

\begin{tabular}{lccccccc}
\hline \hline$x$ & Phase & $a(\AA)$ & $b(\AA)$ & $c(\AA)$ & Angle $\left({ }^{\circ}\right)$ & $V_{\text {exp }}(\%)$ & $V_{\text {cal }}(\%)$ \\
\hline 0.1 & $A B \mathrm{O}_{3}$ & $5.504(4)$ & $5.538(3)$ & $7.838(8)$ & $91.1(1)$ & 22 & 24 \\
& $A_{2} B_{2} \mathrm{O}_{7}$ & $10.724(9)$ & & & & 78 & 76 \\
0.2 & $A B \mathrm{O}_{3}$ & $5.500(2)$ & $5.541(1)$ & $7.839(13)$ & $91.0(1)$ & 45 & 46 \\
& $A_{2} B_{2} \mathrm{O}_{7}$ & $10.722(9)$ & & & & 55 & 54 \\
0.3 & $A B \mathrm{O}_{3}$ & $5.491(3)$ & $5.538(2)$ & $7.822(9)$ & $90.8(1)$ & 63 & 66 \\
& $A_{2} B_{2} \mathrm{O}_{7}$ & $10.716(7)$ & & & & 37 & 34 \\
0.5 & $A_{2} B_{2} \mathrm{O}_{7}$ & $10.728(10)$ & & & & \\
\hline \hline
\end{tabular}


TABLE III. ${ }^{57} \mathrm{Fe}$ and ${ }^{119} \mathrm{Sn}$ Mössbauer parameters of $\mathrm{La}_{1-x} \mathrm{Sn}_{x} \mathrm{Mn}_{0.985} \mathrm{Fe}_{0.015} \mathrm{O}_{3+\delta}(x=0.3$ and 0.5$)$ at $T=300 \mathrm{~K}$. Here, $\delta$ is the isomer shift with respect to $\alpha$-Fe, $\epsilon$ is the quadrupole splitting, $\Gamma$ is the linewidth, and $S$ is the relative area.

\begin{tabular}{lccccc}
\hline \hline Sample & Phase & $\delta(\mathrm{mm} / \mathrm{s})$ & $\epsilon(\mathrm{mm} / \mathrm{s})$ & $\Gamma(\mathrm{mm} / \mathrm{s})$ & $S(\%)$ \\
\hline$x=0.5$ & $A_{2} B_{2} \mathrm{O}_{7}$ & $0.35(3)$ & $1.47(3)$ & 0.49 & 100 \\
$x=0.3$ & $A_{2} B_{2} \mathrm{O}_{7}$ & 0.36 & 1.51 & 0.42 & 48.3 \\
& $A B \mathrm{O}_{3}$ & 0.38 & 0.36 & 0.42 & 51.7 \\
& & & $119 \mathrm{Sn}$ & & \\
$x=0.5$ & $A_{2} B_{2} \mathrm{O}_{7}$ & $0.15(3)$ & $0.52(3)$ & 1.27 & 100 \\
$x=0.3$ & $A_{2} B_{2} \mathrm{O}_{7}$ & $0.16(3)$ & 0.65 & 1.42 & 100 \\
\hline \hline
\end{tabular}

hyperfine parameters are listed in Table IV. The Mössbauer spectrum of $\mathrm{La}_{0.5} \mathrm{Sn}_{0.5} \mathrm{Mn}_{0.985} \mathrm{Fe}_{0.015} \mathrm{O}_{3+\delta}$ is a sextet. The hyperfine field is $474 \mathrm{kOe}$. The Mössbauer spectrum of $\mathrm{La}_{0.7} \mathrm{Sn}_{0.3} \mathrm{Mn}_{0.985} \mathrm{Fe}_{0.015} \mathrm{O}_{3+\delta}$ consists of two sextets. The hyperfine fields are 474 and $525 \mathrm{kOe}$, corresponding to the phases $A_{2} B_{2} \mathrm{O}_{7}$ and $A B \mathrm{O}_{3}$, respectively.

After a longitudinal magnetic field of $50 \mathrm{kOe}$ was applied, for $A B \mathrm{O}_{3}$, the second and fifth lines disappear and, as compared to $525 \mathrm{kOe}$ in zero applied field, the hyperfine field (576 kOe) increases by $51 \mathrm{kOe}$, which is almost the same as the value of the applied field. This means that the Fe moments are collinear but antiparallel with the Mn moments.

However, for $A_{2} B_{2} \mathrm{O}_{7}$, the Mössbauer spectrum is still a sextet without line broadening; therefore antiferromagnetic coupling between the Fe moments is excluded. The nonzero second and fifth lines imply that Fe moments are canted with ferromagnetic coupling or are in a spin-glass state, although ac susceptibility has shown that Mn ions have antiferromagnetic arrangements. ${ }^{7}$ The hyperfine field is $514 \mathrm{kOe}$, larger by $40 \mathrm{kOe}$ as compared to the hyperfine field with zero applied field.

\section{3. ${ }^{57} \mathrm{Fe}$ Mössbauer spectra between $\mathrm{T}=300$ and $4.2 \mathrm{~K}$}

Mössbauer spectra of $\mathrm{La}_{1-x} \mathrm{Sn}_{x} \mathrm{Mn}_{0.985} \mathrm{Fe}_{0.015} \mathrm{O}_{3+\delta}$ with $x=0.3$ and 0.5 between $T=300$ and $4.2 \mathrm{~K}$ have been col-

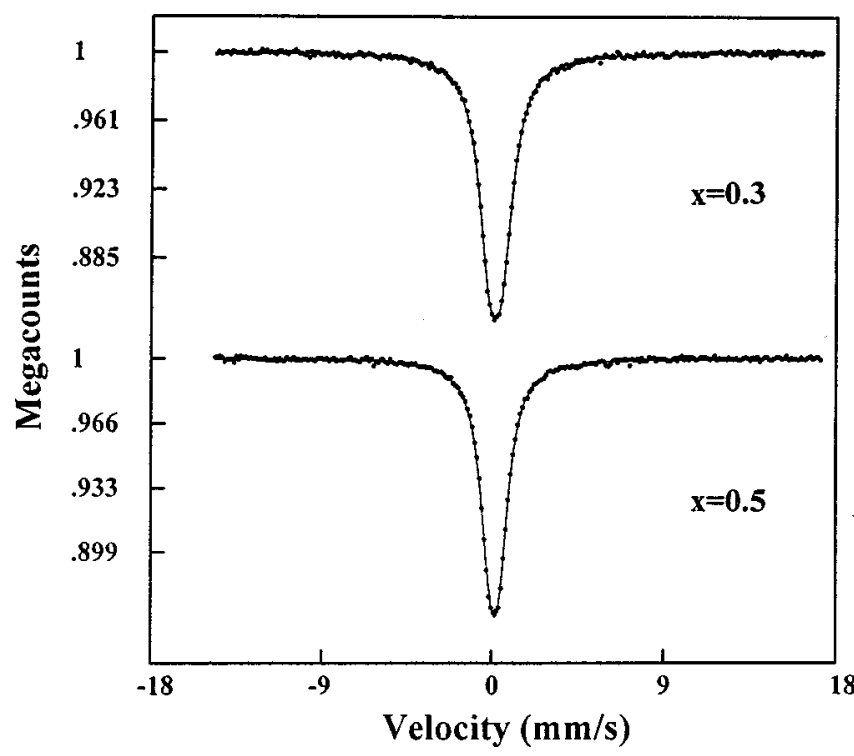

FIG. 5. ${ }^{119} \mathrm{Sn}$ Mössbauer spectra at room temperature for $\mathrm{La}_{1-x} \mathrm{Sn}_{x} \mathrm{Mn}_{0.985} \mathrm{Fe}_{0.015} \mathrm{O}_{3+\delta}$ with $x=0.3$ and 0.5 .

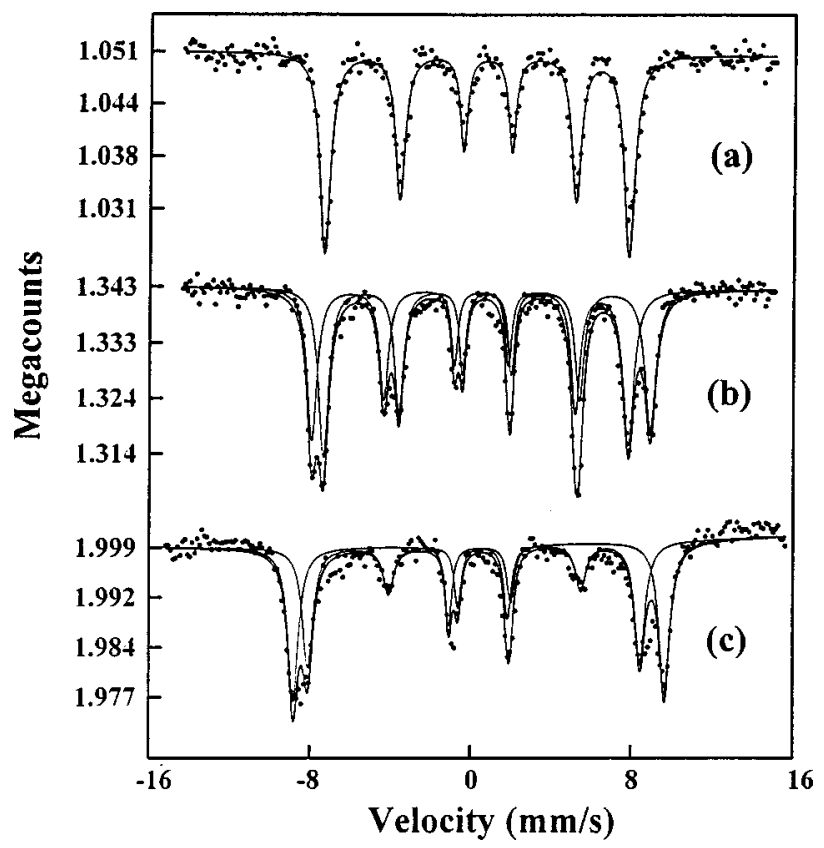

FIG. 6. At $T=4.2 \mathrm{~K}{ }^{57} \mathrm{Fe}$ Mössbauer spectra of (a) $\mathrm{La}_{0.5} \mathrm{Sn}_{0.5} \mathrm{Mn}_{0.985} \mathrm{Fe}_{0.015} \mathrm{O}_{3+\delta}$ and of $\mathrm{La}_{0.7} \mathrm{Sn}_{0.3} \mathrm{Mn}_{0.985} \mathrm{Fe}_{0.015} \mathrm{O}_{3+\delta}$ (b) in zero field and (c) in a longitudinal applied field of $50 \mathrm{kOe}$.

lected. The Mössbauer spectra of the sample with $x=0.5$ are a paramagnetic doublet from room temperature to $65 \mathrm{~K}$. The doublet starts to disappear and becomes a sextet between 65 and $50 \mathrm{~K}$. Therefore, the magnetic ordering temperature is between 65 and $50 \mathrm{~K}$.

The Mössbauer spectra of the sample with $x=0.3$ between 300 and $4.2 \mathrm{~K}$ are shown in Fig. 7. At room temperature two paramagnetic doublets are observed. The inner doublet $\left(A B \mathrm{O}_{3}\right)$ starts to become a mixture of a doublet and a sextet below $250 \mathrm{~K}$. However, the outer doublet $\left(A_{2} B_{2} \mathrm{O}_{7}\right)$ remains until $T=65 \mathrm{~K}$. Only below $65 \mathrm{~K}$ does the outer doublet disappear and spectra consist of two sextets. Therefore, $\mathrm{La}_{0.7} \mathrm{Sn}_{0.3} \mathrm{Mn}_{0.985} \mathrm{Fe}_{0.015} \mathrm{O}_{3+\delta}$ has two transitions which occur at $T=250$ and $65 \mathrm{~K}$, respectively; the result is supported by ac susceptibility data. ${ }^{7}$ In addition, the spectra of $A B \mathrm{O}_{3}$ exhibit a superparamagneticlike character, described in detail by Sec. IV.

TABLE IV. ${ }^{57} \mathrm{Fe}$ Mössbauer parameters of $\mathrm{La}_{1-x} \mathrm{Sn}_{x} \mathrm{Mn}_{0.985} \mathrm{Fe}_{0.015} \mathrm{O}_{3+\delta}(x=0.3$ and 0.5$)$ in zero and a $50 \mathrm{kOe}$ applied field at $T=4.2 \mathrm{~K}$. Here, $\delta$ is the isomer shift with respect to $\alpha$-Fe, $\epsilon$ is the quadrupole splitting, $H_{\mathrm{hf}}$ is the hyperfine field, $b$ is the area ratio of the second plus fifth to the third plus fourth and $S$ is the relative area.

\begin{tabular}{ccccccc}
\hline \hline \multicolumn{7}{c}{$H_{a}=0 \mathrm{kOe}$} \\
Sample & Phase & $\delta(\mathrm{mm} / \mathrm{s})$ & $\epsilon(\mathrm{mm} / \mathrm{s})$ & $H_{\mathrm{hf}}(\mathrm{kOe})$ & $b$ & $S(\%)$ \\
\hline$x=0.5$ & $A_{2} B_{2} \mathrm{O}_{7}$ & $0.50(3)$ & $-0.46(3)$ & $474(3)$ & 2.0 & 100 \\
$x=0.3$ & $A_{2} B_{2} \mathrm{O}_{7}$ & 0.51 & -0.64 & 474 & 2.0 & 47.4 \\
& $A B \mathrm{O}_{3}$ & 0.50 & 0.03 & 525 & 2.0 & \\
& & \multicolumn{7}{c}{$H_{a}=50 \mathrm{kOe}$} \\
$x=0.3$ & $A_{2} B_{2} \mathrm{O}_{7}$ & $0.47(3)$ & $-0.41(3)$ & $514(3)$ & 1.30 & 50.1 \\
& $A B \mathrm{O}_{3}$ & 0.56 & 0.04 & 576 & 0.0 & 49.9 \\
\hline \hline
\end{tabular}




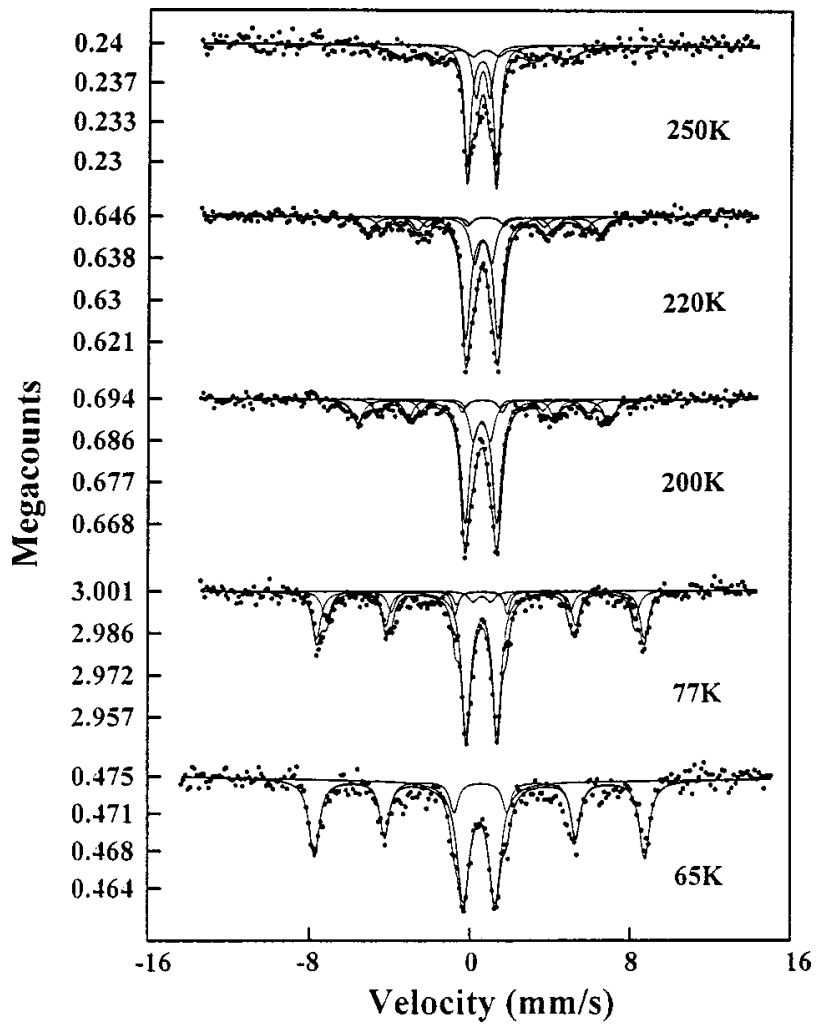

FIG. 7. ${ }^{57} \mathrm{Fe}$ Mössbauer spectra from 250 to $65 \mathrm{~K}$ for $\mathrm{La}_{0.7} \mathrm{Sn}_{0.3} \mathrm{Mn}_{0.985} \mathrm{Fe}_{0.015} \mathrm{O}_{3+\delta}$.

\section{DISCUSSION}

\section{A. Phase compositions}

The ${ }^{57} \mathrm{Fe}$ Mössbauer spectrum at room temperature has two subspectra for $\mathrm{La}_{0.7} \mathrm{Sn}_{0.3} \mathrm{Mn}_{0.985} \mathrm{Fe}_{0.015} \mathrm{O}_{3+\delta}$ and only one for $\mathrm{La}_{0.5} \mathrm{Sn}_{0.5} \mathrm{Mn}_{0.985} \mathrm{Fe}_{0.015} \mathrm{O}_{3+\delta}$. This shows that $\mathrm{Mn}(\mathrm{Fe})$ ions are located in two phases for the sample with $x=0.3$ and only one in the $A_{2} B_{2} \mathrm{O}_{7}$ phase for the sample with $x=0.5$ (Fig. 4). However, ${ }^{119}$ Sn Mössbauer spectra at room temperature have only one component for both samples. Further, isomer shifts and quadrupole splittings are almost the same, as shown in Sec. III B 1. This shows that the $\mathrm{Sn}$ ions are only in the $A_{2} B_{2} \mathrm{O}_{7}$ phase.

It is known that the ion radii are much larger for $\mathrm{La}^{3+}$ $(1.032 \AA)$ than for $\mathrm{Sn}^{4+}(0.69 \AA)$. Consequently, with $\mathrm{Sn}$ substitution for La the lattice parameters should have been significantly reduced. However, XRD results show that when the $\mathrm{Sn}$ concentrations change from 0.1 to 0.5 the lattice parameters are almost constant within the experimental errors for $A_{2} B_{2} \mathrm{O}_{7}$ and $A B \mathrm{O}_{3}$. This implies that the phase compositions are the same in each phase for all samples.

Quantitative analysis of XRD is also able to confirm that the $\mathrm{Sn}$ ions are located in $A_{2} B_{2} \mathrm{O}_{7}$. It is supposed that all $\mathrm{Sn}$ ions are in $A_{2} B_{2} \mathrm{O}_{7}$ and none are in $A B \mathrm{O}_{3}$; in other words, the chemical formulas are $\mathrm{LaMnO}_{3+\delta}$ and $\left(\mathrm{La}_{0.5} \mathrm{Sn}_{0.5}\right)_{2} \mathrm{Mn}_{2} \mathrm{O}_{7}$ for the $A B \mathrm{O}_{3}$ and $A_{2} B_{2} \mathrm{O}_{7}$ phases, respectively. The relative amounts, $C_{227}$ and $C_{113}$, of the two phases can be obtained from the Sn concentration $x$, the cell volumes $V_{227}$ and $V_{113}$, and the cell number per chemical formula $N_{227}$ and $N_{113}$,

$$
\frac{C_{227}}{C_{113}}=\frac{x}{1-2 x} \frac{V_{227} / N_{227}}{V_{113} / N_{113}},
$$
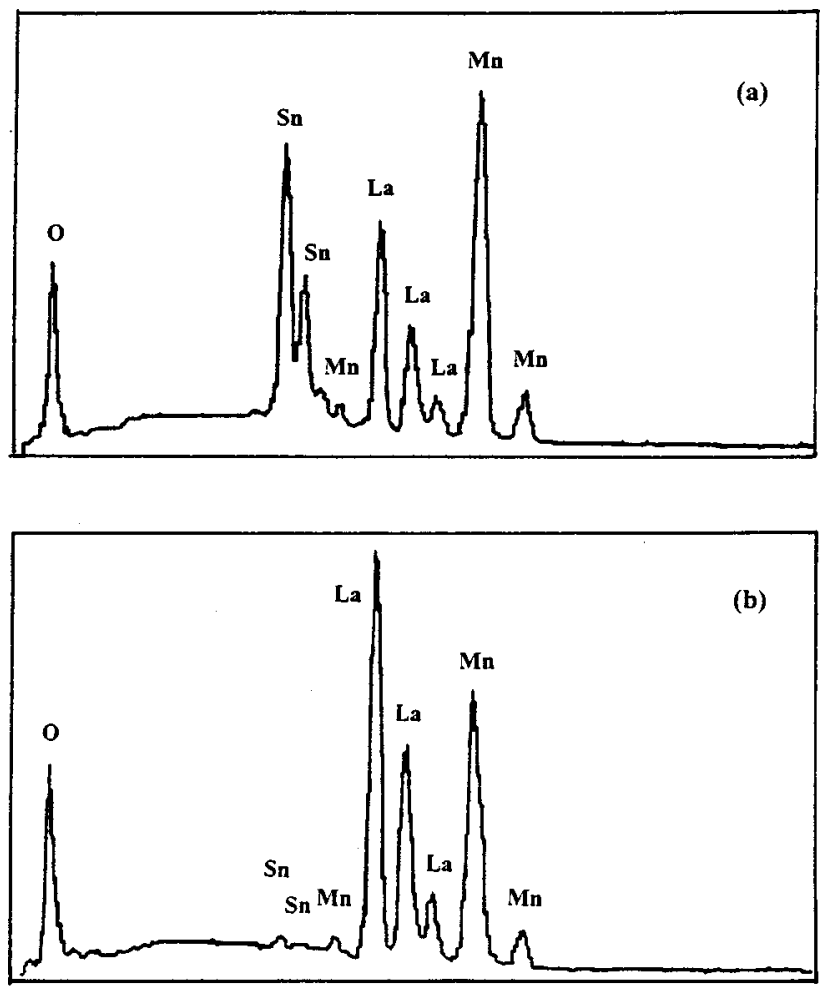

\section{Energy}

FIG. 8. Energy-dispersive spectra $(0-10.24 \mathrm{keV})$ for $\mathrm{La}_{0.9} \mathrm{Sn}_{0.1} \mathrm{MnO}_{3+\delta}$; the percentage of $\mathrm{La}, \mathrm{Sn}$, and $\mathrm{Mn}$ atoms is (a) 21.9:24.9:53.2 and (b) 48.6:1.6:49.8 corrected for atomic number effect, absorption of $\mathrm{x}$ rays within the specimen, and fluoresence effects (the ZAF technique).

where the volumes are $V_{227}=1232 \AA$ and $V_{113}=239 \AA$, determined by the lattice parameters, and $N_{227}=8$ and $N_{113}$ $=4$ based on the crystal structures. The calculated results are $C_{227}: C_{113}=24: 76,46: 54$, and $66: 34$ for the samples with $x=0.1,0.2$, and 0.3 , respectively. These ratios are very consistent with the values obtained from quantitative analysis of XRD, as shown in Table II.

Energy dispersive spectroscopy (EDS) quantitative analysis also indicated the concentrations of $\mathrm{La}, \mathrm{Sn}$, and $\mathrm{Mn}$ averaged over many grains are very close to the formula $\mathrm{La}_{1-x} \mathrm{Sn}_{x} \mathrm{MnO}_{3+\delta}$ for all samples. A homogeneous composition distribution of $\mathrm{La}, \mathrm{Sn}$, and $\mathrm{Mn}$ is observed everywhere for $\mathrm{La}_{0.5} \mathrm{Sn}_{0.5} \mathrm{MnO}_{3+\delta}$. However, it was found that for the other samples with $x=0.1,0.2$, and 0.3 there exist two kinds of grains in which the compositions are significantly different. For one, the quantity of La plus Sn ions is close to that of $\mathrm{Mn}$ ions; for the other grain, there is an equal number of La and Mn ions but almost no Sn ion as shown in Fig. 8.

Based on the XRD, EDS, and Mössbauer spectra, the manganites $\mathrm{La}_{1-x} \mathrm{Sn}_{x} \mathrm{MnO}_{3+\delta}$ with $x=0.1,0.2$, and 0.3 are a mixture of two phases, $\mathrm{ABO}_{3}$ and $\mathrm{A}_{2} \mathrm{~B}_{2} \mathrm{O}_{7}$; the formulas are $\mathrm{LaMnO}_{3+\delta}$ and $\left(\mathrm{La}_{0.5} \mathrm{Sn}_{0.5}\right)_{2} \mathrm{Mn}_{2} \mathrm{O}_{7}$, respectively. The amount of the two phases is dependant on the Sn concentrations. With increasing $\mathrm{Sn}$ substitution, the amount of $A B \mathrm{O}_{3}$ decreases and that of $A_{2} B_{2} \mathrm{O}_{7}$ increases. Therefore, the maximum magnetoresistance coefficient and the $\mathrm{S}-\mathrm{M}$ transition temperature are roughly the same for all the samples with $\mathrm{Sn}$ concentration $x=0.1,0.2$, and 0.3 ; but the resistivities become large with increasing $\mathrm{Sn}$ substitution. In addition, at the 
Sn concentration $x=0.5,\left(\mathrm{La}_{0.5} \mathrm{Sn}_{0.5}\right)_{2} \mathrm{Mn}_{2} \mathrm{O}_{7}$ is a single phase.

The CMR and S-M transition in $\mathrm{La}_{1-x} \mathrm{Sn}_{x} \mathrm{MnO}_{3+\delta}$ occurs at $T=235-245 \mathrm{~K}$. The $\mathrm{ABO}_{3}$ phase has a magnetic transition at about $240 \mathrm{~K}$. Consequently, the CMR in $\mathrm{La}_{1-x} \mathrm{Sn}_{x} \mathrm{MnO}_{3+\delta}$ with $x=0.1,0.2$, and 0.3 is associated with the $A B \mathrm{O}_{3}$ phase. It is known that $\mathrm{LaMnO}_{3}$ is an antiferromagnetic insulator. However, a deficiency of La and/or $\mathrm{Mn}$ ions can lead to a CRM. Results of the CMR in $\mathrm{La}_{1-x} \mathrm{MnO}_{3}$ and $\mathrm{LaMnO}_{3+\delta}$ have been reported recently. ${ }^{16-18}$ Our work also indicates that $\mathrm{La}_{0.9} \mathrm{MnO}_{3+\delta}$ has a S-M transition at $T=240 \mathrm{~K}$, a paramagnetic-ferromagnetic transition at $T=250 \mathrm{~K}$, and the CMR is about $26 \%$ in $H$ $=15 \mathrm{kOe}$ at $T=240 \mathrm{~K}^{19}$ Hence, the CMR in $\mathrm{La}_{1-x} \mathrm{Sn}_{x} \mathrm{MnO}_{3+\delta}$ may have its origin in a deficiency of $\mathrm{La}$ and/or $\mathrm{Mn}$ ions for the $\mathrm{ABO}_{3}$ phase.

\section{B. Superparamagneticlike behavior and CMR}

Between the temperature range of 250 and $65 \mathrm{~K}$, the Mössbauer spectra of the $A B \mathrm{O}_{3}$ phase $\left(\mathrm{LaMnO}_{3+\delta}\right)$ in $\mathrm{La}_{0.7} \mathrm{Sn}_{0.3} \mathrm{Mn}_{0.985} \mathrm{Fe}_{0.015} \mathrm{O}_{3+\delta}$ can be fitted with three subspectra, as shown in Fig. 7. One is a doublet; the others are sextets. One sextet is expected when Fe ions substitute for the Mn ions which occupy only one site in the perovskite structure; the other may have one or more sources, viz (a) Fe ions in a defect structure produced by the deficiency of La-Mn ions, (b) near the surface ${ }^{15}$ and (3) perhaps with different numbers of Fe-Mn neighbors. In addition, the Curie temperature is $235 \mathrm{~K}$ for $\mathrm{La}_{0.7} \mathrm{Sn}_{0.3} \mathrm{Mn}_{0.985} \mathrm{Fe}_{0.015} \mathrm{O}_{3+\delta} .{ }^{4}$ However, a hyperfine field at $T=250 \mathrm{~K}$ was observed above the Curie temperature, as shown in Figs. 7 and 9(d). A similar observation in the $\mathrm{La}-\mathrm{Sr}-\mathrm{Mn}(\mathrm{Fe})-\mathrm{O}$ system was also reported by Tkachuk et al. ${ }^{20}$ The hyperfine fields above the Curie temperature may be attributed to sample inhomogeneity or to a formation of local ferromagnetic clusters at $\mathrm{Fe}$ sites. $^{20}$

The spectra of $\mathrm{LaMn}(\mathrm{Fe}) \mathrm{O}_{3+\delta}\left(A B \mathrm{O}_{3}\right)$ exhibit the following superparamagnetic characteristics. (1) The spectra consist of a doublet and two sextets. With decreasing temperatures, the relative areas of the sextets gradually increase whereas that of the doublet gradually decreases to zero below $T=65 \mathrm{~K}$, as shown in Fig. 9(a). (2) The quadrupole splittings of the doublet between 220 and $65 \mathrm{~K}$ are approximately constant and significantly different from that at room temperature (in the paramagnetic state), as shown in Fig. 9(b). (3) The fitted linewidth is approximately the same for either the sextets or the doublet, except for the linewidth at $T=250 \mathrm{~K}$, as shown in Fig. 9(c). The linewidths of $\mathrm{LaMn}(\mathrm{Fe}) \mathrm{O}_{3+\delta}$ are significantly different from those of La$\mathrm{Ca}-\mathrm{Mn}(\mathrm{Fe})-\mathrm{O}$ and $\mathrm{La}-\mathrm{Sr}-\mathrm{Mn}(\mathrm{Fe})-\mathrm{O}$ in which line broadening of the sextets has been observed with increasing temperatures. ${ }^{20,21}$ The broadening was interpreted using a model based either on an antiferromagnetic impurity in a ferromagnetic host ${ }^{21}$ or on spin fluctuations. ${ }^{20}$

However, the particle sizes of the sample are of the order of micrometers based on observations with optical microscopy. Further, line broadening is not observed in x-raydiffraction patterns. These results exclude the possibility of superparamagnetism produced by ultrafine particles. Per-

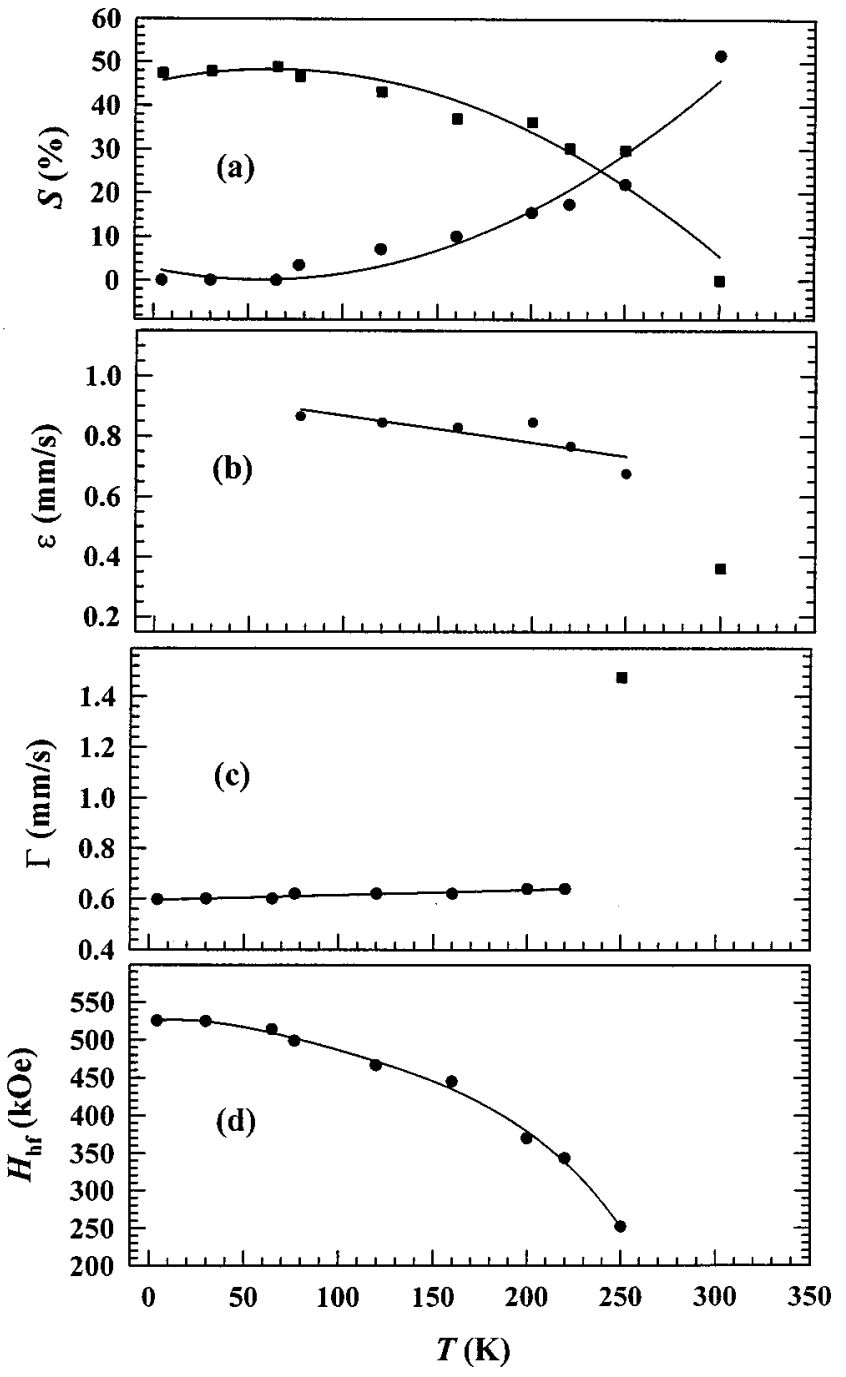

FIG. 9. Some Mössbauer parameters of the $\mathrm{ABO}_{3}$ phase for sample $\mathrm{La}_{0.7} \mathrm{Sn}_{0.3} \mathrm{Mn}_{0.985} \mathrm{Fe}_{0.015} \mathrm{O}_{3+\delta}$, (a) the relative areas for the doublet (circles) and the sextet (squares), (b) the quadrupole splittings for the doublet, (c) linewidth for the sextet, and (d) hyperfine field for the sextet.

haps, the superparamagnetism has its origin in superparamagneticlike spin clusters at $\mathrm{Fe}$ sites. ${ }^{22}$

The dependence of $\Delta \rho / \rho(0)$ on the applied field $H$ can be fitted using a Langevin function

$$
\Delta \rho(H) / \rho(0)=-\beta[\operatorname{coth}(\alpha)-1 / \alpha],
$$

where $\alpha=N \mu_{B} H / k T, \mu_{B}$ is the Bohr magneton, and $k$ is Boltzmann's constant. $N$ and $\beta$ are fitted parameters. $N$ is the average number of spin in a superparamagneticlike cluster, namely, the average size of the clusters. $\beta$ is the maximum MR as $H \rightarrow \infty$ at a certain temperature. The fitted curves are shown in Fig. 10. Obviously, the experimental $\Delta \rho / \rho(0)$ is very consistent with the Langevin curves. The behavior of the magnetoresistance in applied fields is related to the average spin numbers in a cluster, namely the average size of a cluster. When the temperature drops, the size of a cluster decreases and the CMR also decreases.

In this work, no evidence was found as to whether the sample without Fe doping, $\mathrm{La}_{0.7} \mathrm{Sn}_{0.3} \mathrm{MnO}_{3+\delta}$, has a superparamagneticlike spin clusters. This is an interesting problem that will be further studied. 


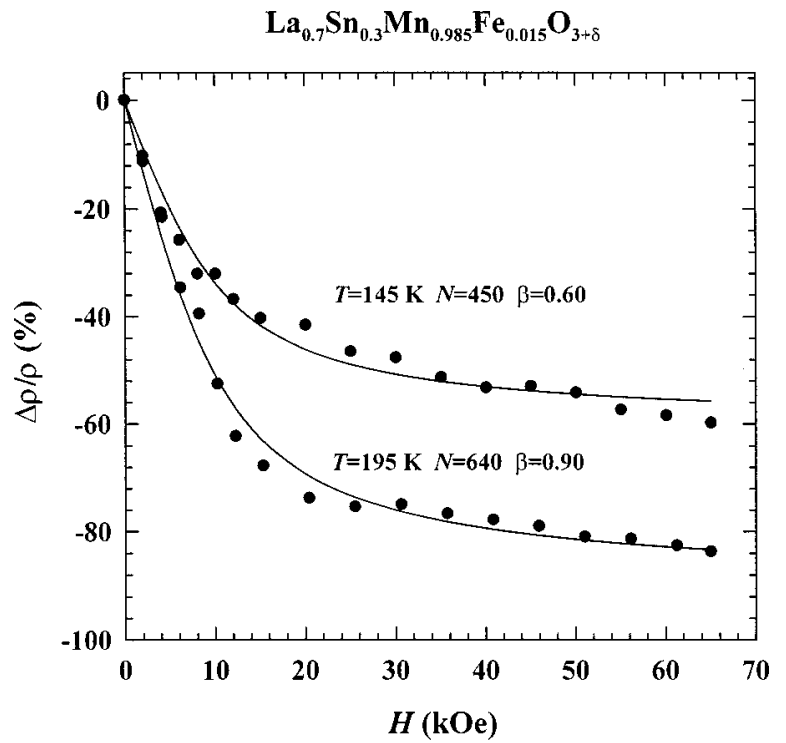

FIG. 10. The magnetoresistance coefficient-applied field curves for $\mathrm{La}_{0.7} \mathrm{Sn}_{0.3} \mathrm{Mn}_{0.985} \mathrm{Fe}_{0.015} \mathrm{O}_{3+\delta}$ and the fitting curves based on a Langevin function.

According to the double-exchange model, the resistivity depends on electron-spin alignment of the hopping electron and is decreased by applying a magnetic field or by reducing the temperatures that reduce the spin disorder. As compared to $\mathrm{LaMnO}_{3+\delta}$, doping with $\mathrm{Fe}$ has two additional effects. Mössbauer spectrum with an applied field of $50 \mathrm{kOe}$ has shown that all Fe moments are collinear but antiparallel with the Mn moments. Antiferromagnetic Fe-O-Mn superexchange interactions would weaken the double-exchange interaction between $\mathrm{Mn}^{3+}$ and $\mathrm{Mn}^{4+}$ ions, as described by Leung et al. ${ }^{15}$ On the other hand, the superparamagneticlike clusters also lead to an increase in electronic scattering below $T_{C}$. Consequently, the resistivity is ten times higher for the Fe-doped sample than for $\mathrm{La}_{0.7} \mathrm{Sn}_{0.3} \mathrm{MnO}_{3+\delta}$ (see Table I). When the magnetic field is applied, the superparamagneticlike clusters are destroyed and the spins tend to alignment along the field. As a result, the resistivity decreases rapidly.

\section{CONCLUSIONS}

Based on the XRD, EDS, and ${ }^{57} \mathrm{Fe}$ and ${ }^{119} \mathrm{Sn}$ Mössbauer spectra, at the Sn concentration $x=0.5, \mathrm{La}_{1-x} \mathrm{Sn}_{x} \mathrm{MnO}_{3+\delta}$ is a single phase $\left(\mathrm{La}_{0.5} \mathrm{Sn}_{0.5}\right)_{2} \mathrm{Mn}_{2} \mathrm{O}_{7}$. At $\mathrm{Sn}$ concentrations $x$ $<5$, the manganites $\mathrm{La}_{1-x} \mathrm{Sn}_{x} \mathrm{MnO}_{3+\delta}$ have two phases. One is $A B \mathrm{O}_{3}$ with the chemical formula $\mathrm{LaMnO}_{3+\delta}$ and the other is $A_{2} B_{2} \mathrm{O}_{7}$ with the formula $\left(\mathrm{La}_{0.5} \mathrm{Sn}_{0.5}\right)_{2} \mathrm{Mn}_{2} \mathrm{O}_{7}$. The CMR in $\mathrm{La}_{1-x} \mathrm{Sn}_{x} \mathrm{MnO}_{3+\delta}$ seems to have its origin in the deficient $\mathrm{La}$ and/or $\mathrm{Mn}$ ions in the $A B \mathrm{O}_{3}$ phase.

The transport properties of $\mathrm{La}_{1-x} \mathrm{Sn}_{x} \mathrm{MnO}_{3+\delta}$ are modified by $\mathrm{Fe}$ doping, which leads to a low saturation field for magnetoresistance, a decrease in the S-M transition temperature and an increase in the resistivity. Mössbauer spectra also indicated that the superparamagnetic doublet persists from $T=250 \mathrm{~K}$ to $77 \mathrm{~K}$ for the $A B \mathrm{O}_{3}$ phase in the Fe-doped sample. The low saturation field may be related to superparamagneticlike spin clusters. Consequently, the CMR reaches $75 \%$ at an applied field of only $20 \mathrm{kOe}$ for the Fe-doped sample; however, the same CMR requires field as high as 70 kOe for $\mathrm{La}_{0.7} \mathrm{Sn}_{0.3} \mathrm{MnO}_{3+\delta}$.

\section{ACKNOWLEDGMENTS}

The financial support of the Natural Sciences and Engineering Research Council of Canada is acknowledged. The authors thank J.H. Zhao and X. Z. Zhou for assistance with the CMR measurements.
${ }^{1}$ S. Jin, H.M. O'Bryan, T.H. Tiefel, M. McCormack, and W.W. Rhodes, Appl. Phys. Lett. 66, 382 (1990).

${ }^{2}$ Y. Shimakawa, Y. Kubo, and T. Manako, Nature (London) 379, 53 (1996)

${ }^{3}$ M.A. Subramanian, B.H. Toby, A.P. Ramirez, W.J. Marshall, A.W. Sleight, and G.H. Kwei, Science 273, 81 (1996).

${ }^{4}$ S. Dai, Z.W. Li, A.H. Morrish, X.Z. Zhou, J.G. Zhao, and X.M. Xiong, Phys. Rev. B 55, 14125 (1997).

${ }^{5}$ A.H. Morrish, Z.W. Li, S. Dai, X.Z. Zhou, J.G. Zhao, and X.M. Xiong, Hyperfine Interact. 113, 485 (1998).

${ }^{6}$ V.N. Krivoruchko, V.P. Pashchenko, Yu V. Medverdev, S.L. Khartsev, A.A. Shemyakov, M.M. Savosta, V.I. Kamenev, A.D. Loyko, G.K. Volkova, and V.I. Volkov, Phys. Lett. A 245, 163 (1998).

${ }^{7}$ Z.W. Li, A.H. Morrish, and X.Z. Zhou, J. Appl. Phys. 83, 7198 (1998).

${ }^{8}$ L. Righi, P. Gorria, M. Insausti, J. Guitierrez, and J.M. Barandiaran, J. Appl. Phys. 81, 5767 (1997).

${ }^{9}$ K.H. Ahn, X.W. Wu, K. Liu, and C.L. Chien, Phys. Rev. B 54, 15 299 (1996).

${ }^{10}$ Y. Tokura, A. Urushibara, Y. Moritomo, T. Arima, A. Asamitsu, G. Kido, and N. Furukawa, J. Phys. Soc. Jpn. 63, 3931 (1994).

${ }^{11}$ D. Emin and N.L.H. Liu, Phys. Rev. B 27, 4788 (1983).
${ }^{12}$ M.H. Hundley, M. Hawley, R.H. Heffiner, Q.X. Jia, J.J. Neumeier, J. Tesmer, J.D. Thompson, and X.D. Wu, Appl. Phys. Lett. 67, 860 (1995).

${ }^{13}$ C.G. Whinfrey, D.W. Eckart, and A. Tauber, J. Am. Chem. Soc. 82, 2695 (1960).

${ }^{14}$ T. Hashimoto, J. Cryst. Growth 84, 207 (1987).

${ }^{15}$ L.K. Leung, A.H. Morrish, and B.J. Evans, Phys. Rev. B 13, 4069 (1976).

${ }^{16}$ M. Verels, N. Rangavittal, C.N.R. Rao, and A. Rousset, J. Solid State Chem. 104, 74 (1993).

${ }^{17}$ T.R. McGuire, A. Gupta, P.R. Duncombe, M. Rupp, J.Z. Sun, R.B. Laibowitz, and W.J. Gallagher, J. Appl. Phys. 79, 4549 (1996).

${ }^{18}$ A. Maignan, C. Michel, M. Hervieu, and B. Raveau, Solid State Commun. 101, 277 (1996).

${ }^{19}$ Z. W. Li and A. H. Morrish (unpublished).

${ }^{20}$ A. Tkachuk, K. Rogacki, D.E. Brown, B. Dabrowski, A.J. Fedro, C.W. Kimball, B. Pyles, X. Xiong, D. Rosenmann, and B.D. Dunlap, Phys. Rev. B 57, 8509 (1998).

${ }^{21}$ A. Simopoulos, M. Pissas, G. Kallias, E. Devlin, N. Moutis, I. Panagiotopoulos, D. Niarchos, C. Christides, and R. Sonntag, Phys. Rev. B 59, 1263 (1999).

${ }^{22}$ D. Barlett, F. Tsui, D. Glick, L. Lauhon, T. Mandrekar, C. Uher, and R. Clarke, Phys. Rev. B 49, 1521 (1994). 